\title{
Obituaries
}

\section{J.V. P. Long (1926-2003)}

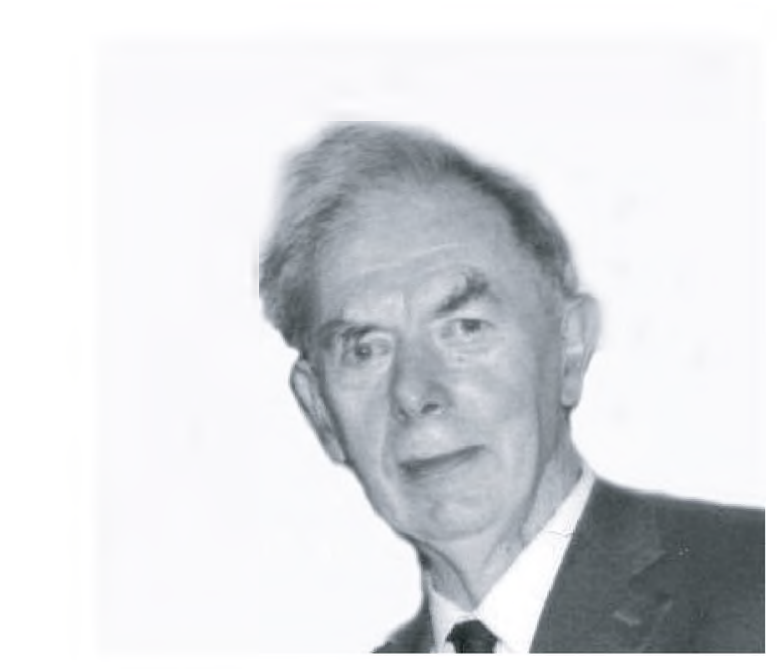

Jim Long was born in Winchester in 1926. After attending Peter Symonds' Grammar School he went up to Cambridge University (Christ's College) to read Natural Sciences, with physics as his main subject, and was awarded the BA degree in 1945. After working at RAE Farnborough for a year, he moved to the National Chemical Laboratory, Teddington, where he worked on radioactive isotopes. In 1954 he joined the Electron Microscope Section in the Cavendish Laboratory, Cambridge, under Dr V.E. Cosslett. The work which led to the award of the $\mathrm{PhD}$ degree in 1958 included the construction of an electron microprobe. Compared with the few other existing instruments, this was a remarkably simple and compact design and was the first to incorporate a transmitted light microscope for geological applications. At the instigation of Stuart Agrell, Jim moved to the Department of Mineralogy and Petrology (now part of Earth Sciences). A grant was obtained from DSIR (predecessor of today's research councils) for the development of a 'Mark 2' instrument. There followed the development, in collaboration with the Cambridge Instrument Company, of a more advanced design marketed as the Geoscan (of which the
Microscans 5 and 9 were later versions). A highlight of this period was the designation by NASA of Jim and Stuart Agrell as principal investigators of the Apollo 11 lunar samples in 1969. 'Energy-dispersive' X-ray detectors first came on the scene around 1970 and one of these was fitted to the Mark 2 instrument, with some advanced electronics originating from AERE Harwell, leading to the first quantitative ED microprobe in the UK, which was used up to 1989. As well as providing electron probe facilities for 'Min and Pet', a NERC-supported service for researchers from other universities was made available for many years, and numerous theses and publications contain the resulting data.

In the late 1960s Jim embarked on the development of an ion microprobe, leading to the production by AEI Scientific Instruments Ltd of the IM20 instrument, the prototype of which was installed in Cambridge in 1974, marking the start of geological ion microprobe activity in the UK. Jim, of course, soon started thinking about how to make a better instrument, and embarked on the ambitious task of designing an ion microprobe capable of the high mass resolution and high sensitivity required for U-Pb zircon dating, which, though eventually successful, 
unfortunately never became available on a commercial basis. After retirement from his University Readership in 1993, he continued working with the ion probe, also on the development of a high-intensity focused X-ray source for use in X-ray diffractometers (in association with Bede Scientific Ltd).

As well as supervising a series of $\mathrm{PhD}$ students in the course of the developments described above, Jim played a full part in undergraduate teaching and other departmental activities. He was a member of the Mineralogical Society for more than 40 years and served on the Council from 1984 to 1986 . The Society honoured him with a dedicated session at the Winter Meeting in January 1998 at which he received a special presidential award.
Jim was notable for the generosity with which he gave his time to others, and this extended to various activities in his home village of Haslingfield, where he served as parish councillor and school governor, while still finding time to carry out extensive renovations on the old farmhouse acquired in a near-derelict state in the early 1960s, and to run a succession of old Rover cars. He will be greatly missed by all who had the good fortune to encounter him in any of his many roles, and most of all by his wife Margaret (well known to generations of students, visitors and other beneficiaries of the Longs' warm hospitality), son Peter, and two much-loved grandsons.

S.J.B. REED

\section{J. D. H.Wiseman (1907-2002)}

The Society has recently lost one of its most senior members. John Dugdale Holt Wiseman, who died on 14th October 2002 at the age of 95 , joined the Society in 1934 and was a Life Member at the time of his death, still retaining an interest in all three of the Society's major journals.

John Wiseman (Duggie to some) gained his $\mathrm{PhD}$ through the Department of Mineralogy and Petrology at Cambridge University in the early 1930s, studying under Professor C.E. Tilley and Dr A. Harker. His first paper was a contribution to the petrology of metamorphic rocks of East
Greenland, followed by several on related topics until he joined the staff of the Mineralogy Department at the British Museum (Natural History) in 1935, in the same year as G.F. Claringbull.

The Trustees of the Museum had decided in 1935 to separate the oceanic sediments, manganese nodules, and rocks from the much larger zoological collections and John Wiseman was recruited to curate and study the newly amalgamated ocean-bottom collections. The collection were based initially on material provided by Sir

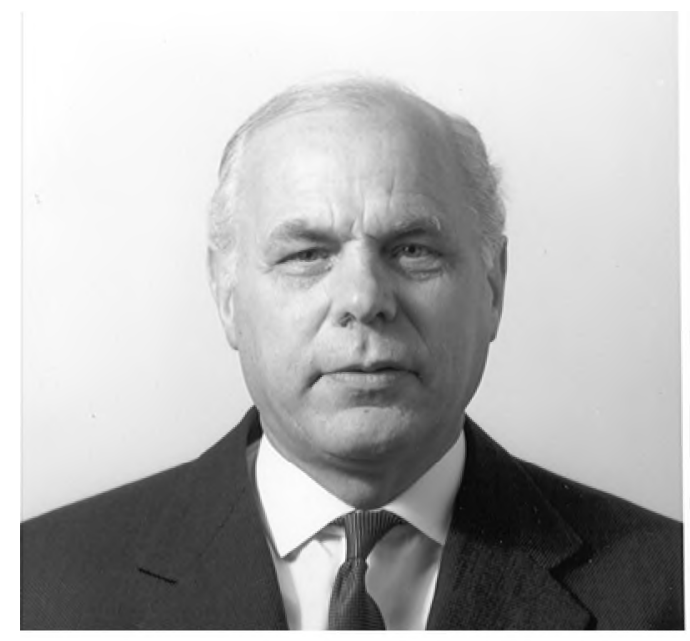

